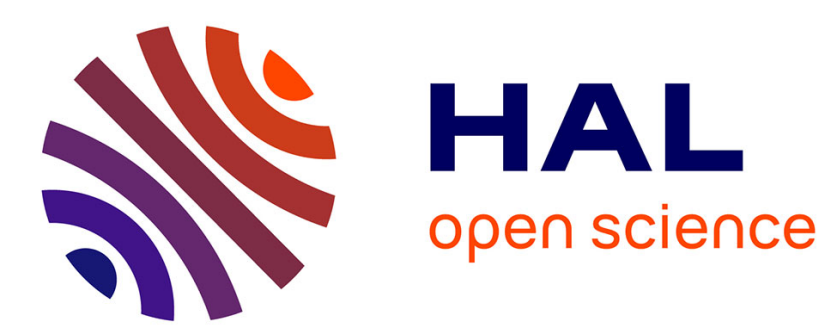

\title{
Insider Trading With Product Differentiation
}

\author{
Wassim Daher, Harun Aydilek, Fida Karam, Asiye Aydilek
}

\section{To cite this version:}

Wassim Daher, Harun Aydilek, Fida Karam, Asiye Aydilek. Insider Trading With Product Differentiation. 2012. halshs-00676502

\section{HAL Id: halshs-00676502 \\ https://shs.hal.science/halshs-00676502}

Submitted on 5 Mar 2012

HAL is a multi-disciplinary open access archive for the deposit and dissemination of scientific research documents, whether they are published or not. The documents may come from teaching and research institutions in France or abroad, or from public or private research centers.
L'archive ouverte pluridisciplinaire HAL, est destinée au dépôt et à la diffusion de documents scientifiques de niveau recherche, publiés ou non, émanant des établissements d'enseignement et de recherche français ou étrangers, des laboratoires publics ou privés. 


\section{Documents de Travail du Centre d'Economie de la Sorbonne}

U NIVERSITÉ PARIS 1

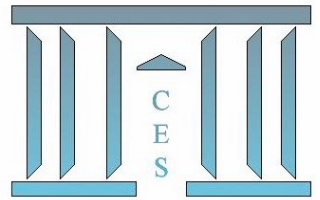

\section{Insider Trading With Product Differentiation}

Wassim DAHER, Harun AYDILEK, Fida KARAM, Asiye AYDILEK

2012.14

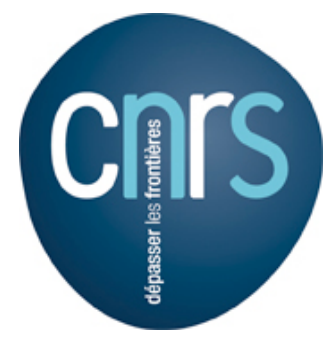

Maison des Sciences Économiques, 106-112 boulevard de L'Hôpital, 75647 Paris Cedex 13 http://centredeconomiesorbonne.univ-paris1.fr/bandeau-haut/documents-de-travail/ 


\title{
Insider Trading With Product Differentiation
}

\author{
Wassim Daher * \\ Harun Aydilek ${ }^{\dagger}$ \\ Fida Karam ${ }^{\ddagger}$ \\ Asiye Aydilek $\S$
}

February 27, 2012

\begin{abstract}
In this paper, we analyze the effect of Cournot competition with differentiated products on the real and financial decisions of a publiclyowned firm, with three different structures in the financial market: monopoly, duopoly and Stackelberg. We show that the degree of product differentiation does not affect the results found in the literature on insider trading, concerning the effect of the financial market structure on firms' outputs, the revelation of information and the insiders' orders. Besides, firms' output, the amount of information revealed in the stock price, the insiders' trading orders and the owners' profits are independent of the degree of product differentiation. The real market structure through the degree of product differentiation is found to determine the level of the compensation scheme earned by the manager, the market makers' response to the total order flow signal as well as the managers' profits. ${ }^{1}$
\end{abstract}

${ }^{*}$ Corresponding author. Department of Mathematics and Natural Sciences, Gulf University for Science and Technology, Kuwait. Email: daher.w@gust.edu.kw

${ }^{\dagger}$ Department of Mathematics and Natural Sciences, Gulf University for Science and Technology, Kuwait. Email: aydilek.h@gust.edu.kw

${ }^{\ddagger}$ Department of Economics and Finance, Gulf University for Science and Technology, Kuwait. Email: karam.f@gust.edu.kw

${ }^{\S}$ Department of Economics and Finance, Gulf University for Science and Technology, Kuwait. Email: aydilek.a@gust.edu.kw

${ }^{1}$ This work was partially developed during a visit of W. Daher and F. Karam to the Sorbonne Economic Centre, Université Paris 1, Panthéon-Sorbonne. W. Daher gratefully acknowledges the financial support of the Sorbonne Economic Centre and thanks particularly, Joseph Abdou, Bernard Cornet and Jean-Marc Bonnisseau. We also thank Leonard Mirman, Fernando Zapatero and the participants to the International Conference on Mathematical Finance and Economics (Istanbul, 2011) for their helpful comments. 
JEL classification: G14, D82

Keywords: Insider trading, Product differentiation, Market structure, Correlated signals, Kyle model

\section{Introduction}

Consumer goods are nowadays available in a variety of styles and labels. Indeed, different brands of cigarettes, toothpaste, shower gel, cosmetics and breakfast foods are on sale in every retail store. Those variations within a product class, referred to as "product differentiation", are designed to spice up the lives of consumers and fulfill the hidden nooks and crannies of their wants. Product differentiation in packaging, design, color, style and location of outlet (horizontal differentiation) or in product quality (vertical differentiation) makes consumer goods imperfect substitutes to each other, thus offering firms market power.

Understanding product differentiation is crucial to perceiving how modern market economies operate. Product differentiation is the outstanding feature of the real world of monopolistic competition initially introduced by Chamberlin (1933). The monopolistic competition structure is characterized by many firms differentiating their products to benefit from market power, with free exit and entry of firms in the long run. This combination of competitive and monopoly elements made the work of Chamberlin so valuable to the modern microeconomic theory and led to interesting theoretical and empirical research on product differentiation (Anderson et al., 1992; Beath and Katsoulacos, 1991; Berry, 1994; Nevo, 1998; Shaked and Sutton, 1982, 1983 and 1987; Sutton, 1986, etc.).

The importance of product differentiation has been highlighted in many fields such as International Trade, Endogenous Growth Theory, New Economic Geography and Macroeconomics. In this paper, we investigate the effect of product differentiation on the transmission of information and on the price of securities. Indeed, in the world of stock markets and firms, information is not or cannot be made public, except by observing market outputs. The type of market structure determines how firms behave, mainly how they choose the quantity produced and the price. In turn, those are taken into consideration by the market maker while chooses the stock price and by the insiders when 
they determine their trading strategies.

In this paper, we analyze insider trading in a static model in the spirit of Kyle (1985) where the insider is also the manager of the firm whose stock he trades in. In the real market, the publicly-owned firm is in competition with another privately-owned firm, producing a horizontally differentiated product. While the effect of Cournot duopoly on the real and financial activities of the firm has been previously tackled in Jain and Mirman (2002), this paper is a first attempt to investigate the effects of Cournot duopoly with differentiated products on insider trading. We first study the effects of product differentiation with a financial market characterized by one insider. Then, we extend the analysis to incorporate another type of competition supposed to affect the price of securities, competition between two insiders in the financial market. Specifically, we analyze the effects of Cournot and Stackelberg competition between the insiders on the benchmark model.

The relation between the real and financial decisions of the firm has been deeply investigated in the theoretical research on insider trading in the spirit of Kyle (1985). The leading paper on this subject was the work of Jain and Mirman (2000). They assume that the insider, who maximizes his profits by trading on the financial market of the firm, is also the manager of that firm who can influence the different variables on the market of the real good and in turn the firm's profits, thus affecting its value in the financial market. Jain and Mirman (2000) first show that with the inclusion of monopoly in the real market, the market maker benefits from an additional source of information, the market price of the real good. Consequently, the stock price reveals more information, in comparison with Kyle (1985) or Rochet and Vila (1994). Many extensions of Jain and Mirman (2000) then follow: Jain and Mirman (2002) assume that the publicly owned firm competes with another one in a Cournot way in the real market. They show that Cournot duopoly in the real sector does not alter the amount of information revealed. However, the insider's profits and his compensation scheme are lower than Jain and Mirman (2000), due to Cournot competition in the real sector. Karam and Daher (2011) assume that the production of the real good by the publicly-owned firm involves constant labor costs as well as costs of intermediate goods produced by another privately-owned firm. They show that insider trading affects the markets of both the final and the intermediate goods, and the financial market variables change due to the insider's real decisions. However, when compared to Jain and Mirman (2000) and (2002), the two-tier real market structure does not alter the amount of information disseminated in the stock price or the level of insider trading. 
Daher and Mirman (2006, 2007) consider another interesting extension of Jain and Mirman (2000, 2002), by modeling Cournot competition between two insiders (the owner and the manager) in the financial market. They show that Cournot competition in the financial sector increases the amount of information incorporated in the stock price with respect to Jain and Mirman $(2000,2002)$. The profits of the manager sometimes increase and sometimes decrease, relatively to Jain and Mirman (2000, 2002), depending on the variances of the exogenous variables. However, the profits of the manager and the owner are lower in the Cournot-real case (Daher and Mirman, 2006) than in the monopoly-real case (Daher and Mirman, 2007). Wang and Wang (2010) introduce Stackelberg competition in the real market to the model of Daher and Mirman (2007) and support the conclusion that competition in the real sector does not affect the degree of information revelation. In Wang et al. (2009), the manager acts as a Stackelberg-follower in the financial sector to the owner who knows the manager's reaction function. The authors show that Stackelberg competition in the financial sector increases the amount of information revealed and the owner's profits, in comparison with Daher and Mirman (2006). The manager's profits may decrease or increase depending on the exogenous parameters of the model.

Daher et al. (2012) investigated the importance of the competition structure in the financial market modeled alone, on the dissemination of information. They start by a natural extension of Jain and Mirman (1999) to include Cournot duopoly in the financial market. Recall that in Jain and Mirman (1999), the marker maker is allowed to observe, in addition to the total order flow, another signal of the value of the asset. The authors show that the stock price reveals more information with respect to Jain and Mirman (1999). The unconditional profits of each insider also decrease. Those results are similar to Daher and Mirman (2007), when compared to Jain and Mirman (2000). They also investigate the effect of Stackelberg competition in the financial market modeled alone and show that the manager (follower) trades less and hence earns less than in the Cournot case. However, the owner (the leader) trades more than in Cournot and earns more profits relative to the Cournot case. They also notice that the price reveals more information in the Stackelberg than in the Cournot structure. Finally, they take into consideration the real activities of the firm with Stackelberg competition in the financial sector. They confirm the results found in the literature that the introduction of the real market does not affect the amount of information revealed in the stock price. 
In this paper, we analyze the effect of Cournot competition with differentiated products on the real and financial decisions of a publicly-owned firm, with three different structures in the financial market: monopoly, duopoly and Stackelberg. We show first that the degree of product differentiation does not alter the results found in the literature on insider trading, concerning the effect of the financial structure on firms' outputs. In other words, the firm's output is lower in the monopoly case than in the duopoly case, and lower in the duopoly case than in the Stackelberg case. Second, as shown in the literature, the financial market structure appears to affect the revelation of information incorporated in the stock price. Indeed, with Stackelberg competition among the insiders, the amount of information revealed in the stock price is greater than in the Cournot case, and greater in the Cournot case than in the monopoly case. Besides, the amount of information revealed in the stock price is independent of the degree of product differentiation. Third, we also find that, in line with the industrial organization theory, the manager's orders in the monopoly case are greater than his orders in the duopoly case which themselves are greater than his orders in the Stackelberg case. Moreover, due to his leadership role in the financial market, the owner's orders are greater under Stackelberg competition than his orders under Cournot competition. We also show that all insiders' orders are independent of the degree of product differentiation. Finally, we show that the owner's profits are not influenced by the real market structure. Indeed, the owner's profits under Stackelberg competition are greater than his profits under the Cournot case. However, the real market structure through the degree of product differentiation is found to determine the level of the compensation scheme earned by the manager, the market makers' response to the total order flow signal as well as the insiders' profits. We show that for these variables, the degree of differentiation and the exogenous variances determine their comparative statics.

The importance of the present paper resides in the fact that it generalizes the previous works on insider trading. Indeed, with extreme values of the product differentiation parameter, we obtain the results of the monopoly and duopoly cases of Jain and Mirman (2000, 2002) with one insider, those of Daher and Mirman $(2007,2006)$ with Cournot competition between two insiders and those of Daher et al. (2012) and Wang et al. (2009) with Stackelberg competition between two insiders.

The paper is structured as follows: In Section 2, we present the benchmark model and its extensions. Section 3 presents the equilibrium results and in Section 4 we discuss the equilibrium outcomes. 


\section{Models}

Let $(\Omega, \mathcal{F}, \mathbb{P})$ be a probability space, all the random variables are defined with respect to this probability space. Consider an economy that consists of differentiated real goods and one financial asset. In the real market, we examine a duopoly where firms sell differientiated goods by setting quantities. The inverse demand facing this industry is linear and stochastic:

$$
q_{i}^{\prime}=\left(a-y_{i}-\theta y_{j}\right) \tilde{z} \quad i, j=1,2 \quad i \neq j, \quad a>0
$$

where $\theta \in(0,1)$ captures the degree of product differentiation: the higher $\theta$, the lower the degree of product differentiation is. The prior distribution of $\tilde{z}$ is normal with mean $\bar{z}$ (assumed to be positive) and variance $\sigma_{z}^{2} \cdot q_{i}^{\prime}$ is the real price of the output $y_{i}$ of firm $i(i=1,2)$. Both firms are standard neoclassical firms with respect to the real sector. With respect to the financial sector, firm 2 is privately owned and privately financed, while firm 1 is publicly owned. In other words, the financial asset is the stock of firm 1 that is publicly traded in a competitive stock market. The value of the asset is the net profits of the firm per share. Firm 1 is managed by an insider whose knowledge can be used in the stock market.

In the financial market, we consider three types of market structures: monopoly, duopoly and Stackelberg competition among the insiders. Those structures will be respectively denoted by Model 1,2 and 3. Without loss of generality, we expose Model 2. ${ }^{2}$ Specifically, there are three types of agents trading in the financial market. First, there are two risk-neutral rational traders: the manager of firm 1 and the "owner", ${ }^{3}$ without any managerial responsibilities. The owner is assumed to have the same private information about the asset as the manager. The two insiders know the realization $z$ of $\tilde{z}$ and trade in the stock market based on their inside information. Second, there are (nonrational) noise traders, representing small investors with no information on $z$. The aggregate noise trade is assumed to be a random variable $\tilde{u}$, which is normally distributed with mean zero and variance $\sigma_{u}^{2}$. Finally, there are $K(K \geq 2)$ risk-neutral market makers who act like Bertrand competitors. We assume, as in Jain and Mirman (2000) (Henceforth, JM), that the market

\footnotetext{
${ }^{2}$ Model 2 generalizes Model 1 and the only difference with Model 3 is the timing of the game. Indeed, in Model 3, the insiders do not trade simultaneously as in Model 2. Instead, the owner moves first and thus takes into account the reaction curve of the manager's trade in his maximization problem. In appendix B, we derive the equilibrium results for Model 3 .

${ }^{3}$ The "owner" is another informed trader (a CEO or a member of the board of directors for example), who does not have any managerial responsibilities.
} 
makers observe two signals, a noisy signal from the real market, denoted by the random variable $\tilde{q}=\left(a-y_{1}-\theta y_{2}\right)(\tilde{z}+\tilde{\varepsilon})$, where $\tilde{\varepsilon}$ is normally distributed with mean zero and variance $\sigma_{\varepsilon}^{2}$, and the total order flow signal. We assume that $\tilde{z}, \tilde{u}$ and $\tilde{\varepsilon}$ are pairwise independent.

Following Kyle (1985), the trading mechanism is organized in two steps. In step one, a linear pricing rule and optimal order rule are determined by the market makers and the insider, respectively, as a Bayesian-Nash equilibrium. The market makers determine a (linear) pricing rule $p$, based on their a priori beliefs, where $p$ is a measurable function $p: \mathbb{R} \times \mathbb{R} \longrightarrow \mathbb{R}$. Each insider $i(i=1,2)$ chooses a stock trade function $\tilde{x}_{i}=x_{i}(\tilde{z})$, where $x_{i}: \mathbb{R} \longrightarrow$ $\mathbb{R}$ is a measurable function. In the second step, the insider observes the realization $z^{4}$ of $\tilde{z}$ and submit his stock order to the market makers based on the equilibrium stock trade functions. The market makers also receive orders from the noise traders. All these orders arrive as a total order flow signal $\tilde{r}=\sum_{i=1}^{2} x_{i}(\tilde{z})+\tilde{u}$. The two signals, the real signal and the order flow signal, are used by the market makers to set the price $\tilde{p}=p(\tilde{q}, \tilde{r})$, based on the equilibrium price function, to clear the market. The insider knows only the value of $\tilde{z}$ and does not know the values of $\tilde{u}, \tilde{\varepsilon}, \tilde{r}, \tilde{z}+\tilde{\varepsilon}$ before his trading strategies are made. Moreover, each market maker does not know the realization $z$ of $\tilde{z}$ but only knows its distribution. Finally, the market makers cannot observe either $x_{i}, u$ or $\varepsilon$.

The value per share of the firm is the net profits of the firm per share. Hence, the values per share of firm 1 and 2 are respectively given by $v^{\prime}=$ $\left(a-y_{1}-\theta y_{2}\right) y_{1} \tilde{z}$ and $v_{2}=\left(a-y_{2}-\theta y_{1}\right) y_{2} \bar{z}$. The profit of the rational trader is:

$$
\Pi_{1}=\left(v^{\prime}-B_{2}-p\right) \cdot \tilde{x}+B_{2} \tilde{x}
$$

where $B_{2}$ is the compensation scheme of the manager. ${ }^{5}$ The compensation scheme of the manager is determined endogenously in order to satisfy the second order condition of the maximization problem of the manager. Thus, after adjusting for the compensation scheme of the manager, the value of firm 1 becomes: $\tilde{v}=v^{\prime}-B_{2}$.

This is a game of incomplete information because the market makers, unlike the insider, do not know the realization of $\tilde{z}$. Hence, we seek for a Bayesian-

\footnotetext{
${ }^{4}$ Random variables are denoted with a tilde. Realized values lack the tilde. The mean of the random variable is denoted with bar.

${ }^{5}$ See Jain and Mirman (2000, 2002) and Daher and Mirman (2006, 2007) for more details.
} 
Nash equilibrium. A Bayesian-Nash equilibrium is a vector of five functions $\left[y_{1}(),. y_{2}(),. x_{1}(),. x_{2}(),. p(.,).\right]$ such that:

(a) Profit maximization of firm 2,

$$
\left(a-y_{2}-\theta y_{1}\right) y_{2} \bar{z} \geq\left(a-y_{2}^{\prime}-\theta y_{1}\right) y_{2}^{\prime} \bar{z}
$$

for any level of output $y_{2}^{\prime}$ produced by the firm 2 ;

(b) Profit maximization of the manager,

$$
\begin{aligned}
& \left.E\left[\left(a-y_{1}-\theta y_{2}\right) y_{1} \tilde{z}-p\left[\left(a-y_{1}-\theta y_{2}\right)(\tilde{z}+\tilde{\varepsilon})\right),\left(x_{1}(\tilde{z})+x_{2}(\tilde{z})+\tilde{u}\right)\right] x_{1}(\tilde{z})\right] \\
\geq & \left.E\left[\left(a-y_{1}^{\prime}-\theta y_{2}\right) y_{1}^{\prime} \tilde{z}-p\left[\left(a-y_{1}^{\prime}-\theta y_{2}\right)(\tilde{z}+\tilde{\varepsilon})\right],\left(x_{1}^{\prime}(\tilde{z})+x_{2}(\tilde{z})+\tilde{u}\right)\right) x_{1}^{\prime}(\tilde{z})\right]
\end{aligned}
$$

for any level of output $y_{1}^{\prime}$ produced by the firm 1 and any alternative trading strategy $x_{1}^{\prime}(\tilde{z})$;

(c) Profit maximization of the owner,

$$
\begin{aligned}
& \left.E\left[\left(a-y_{1}-\theta y_{2}\right) y_{1} \tilde{z}-B_{2}-p\left[\left(a-y_{1}-\theta y_{2}\right)(\tilde{z}+\tilde{\varepsilon})\right),\left(x_{1}(\tilde{z})+x_{2}(\tilde{z})+\tilde{u}\right)\right] x_{2}(\tilde{z})\right] \\
& \left.\geq E\left[\left(a-y_{1}-\theta y_{2}\right) y_{1} \tilde{z}-B_{2}-p\left[\left(a-y_{1}^{-} \theta y_{2}\right)(\tilde{z}+\tilde{\varepsilon})\right],\left(x_{1}(\tilde{z})+x_{2}^{\prime}(\tilde{z})+\tilde{u}\right)\right) x_{2}^{\prime}(\tilde{z})\right]
\end{aligned}
$$

for any alternative trading strategy $x_{2}^{\prime}(\tilde{z})$;

(d) Semi-Strong Market Efficiency: The pricing rule $p(.,$.$) satisfies,$

$$
p(\tilde{q}, \tilde{r})=E[\tilde{v} \mid \tilde{q}, \tilde{r}] .
$$

Note that conditions (1), (2) and (3) define the optimal strategies of the two firms while condition (4) guarantees the zero expected profits for the market makers. The stock price, set by the market makers, is equal to the conditional expectation of the asset value given their information. We restrict our study to linear equilibrium. The normal distributions of the exogenous random variables, together with the particular expression of the demand, enable us to derive and to prove the existence of a unique linear equilibrium.

\section{$3 \quad$ Equilibrium Results}

In order to derive the unique linear equilibrium, we start by solving the maximization problem of the two firms. The objective of firm 2 is to produce an optimal quantity of outputs, $y_{2}($.$) , to maximize,$

$$
v_{2}=\left(a-y_{2}-\theta y_{1}\right) y_{2} \bar{z}
$$


The first order condition is,

$$
y_{2}=\frac{\left(a-\theta y_{1}\right)}{2}
$$

The decision rule of the manager of firm 1 is the pair $\left(y_{1}(\tilde{z}), x_{1}(\tilde{z})\right)$. The manager's expected profits are,

$$
G_{1}=E\left[\left(a-y_{1}-\theta y_{2}\right) y_{1} \tilde{z}-p\left[\left(a-y_{1}-\theta y_{2}\right)(\tilde{z}+\tilde{\varepsilon}),\left(\sum_{i} x_{i}(\tilde{z})+\tilde{u}\right)\right] x_{1}(\tilde{z})\right]
$$

The first order conditions are,

$$
x_{1}(\tilde{z})=\frac{\left(a-y_{1}-\theta y_{2}\right)\left(y_{1}-\mu_{1}\right) \tilde{z}-\mu_{0}-\mu_{2} \tilde{x_{2}}}{2 \mu_{2}} \text { and } y_{1}=\frac{\left(a-\theta y_{2}+\mu_{1}\right)}{2} .
$$

Similarly, the first order condition of the owner's maximization problem is given by,

$$
x_{2}(\tilde{z})=\frac{\left(a-y_{1}-\theta y_{2}\right)\left(y_{1}-\mu_{1}\right) \tilde{z}-\mu_{0}-B_{2}-\mu_{2} \tilde{x_{1}}}{2 \mu_{2}}
$$

Computing the equilibrium quantities in the real sector from (6) and (8), we get,

$$
y_{1}=\frac{2-\theta}{4-\theta^{2}} a+\frac{2}{4-\theta^{2}} \mu_{1} \text { and } y_{2}=\frac{2-\theta}{4-\theta^{2}} a-\frac{\theta}{4-\theta^{2}} \mu_{1}
$$

Arranging for the insiders' trading orders in equations (8) and (9) we obtain,

$$
x_{1}(\tilde{z})=\frac{\left(a-y_{1}-\theta y_{2}\right)\left(y_{1}-\mu_{1}\right) \tilde{z}-\mu_{0}+B_{2}}{3 \mu_{2}}
$$

and

$$
x_{2}(\tilde{z})=\frac{\left(a-y_{1}-\theta y_{2}\right)\left(y_{1}-\mu_{1}\right) \tilde{z}-\mu_{0}-2 B_{2}}{3 \mu_{2}}
$$

First, note that the outputs produced by the two firms are deterministic. This is due to the fact that the variable $\tilde{z}$ is multiplicative ${ }^{6}$ and implies that the trading levels of the insiders, which are a linear function of $\tilde{z}$, are normal random variables. Second, the two signals received by the market makers, i.e. the real signal $\tilde{q}$ and the total order flow signal $\tilde{r}$, are both normal random variables (since $\tilde{z}, \tilde{u}$ and $\tilde{\varepsilon}$ are mutually independent).

\footnotetext{
${ }^{6}$ Perhaps, it would be more interesting to have a model with output that depends on the value of $\tilde{z}$. However, this would be inconsistent with the normality of the trading functions as well as the signals, and would thus be inconsistent with the linearity of the pricing function.
} 


\section{Table1: Equilibrium outcomes}

\begin{tabular}{|c|c|c|c|}
\hline Variables & Monopoly & Duopoly & Stackelberg \\
\hline$y_{1}$ & $\frac{2-\theta}{4-\theta^{2}} a+\frac{2}{4-\theta^{2}} \mu_{1}$ & $\frac{2-\theta}{4-\theta^{2}} a+\frac{2}{4-\theta^{2}} \mu_{1}$ & $\frac{2-\theta}{4-\theta^{2}} a+\frac{2}{4-\theta^{2}} \mu_{1}$ \\
\hline$y_{2}$ & $\frac{2-\theta}{4-\theta^{2}} a-\frac{\theta}{4-\theta^{2}} \mu_{1}$ & $\frac{2-\theta}{4-\theta^{2}} a-\frac{\theta}{4-\theta^{2}} \mu_{1}$ & $\frac{2-\theta}{4-\theta^{2}} a-\frac{\theta}{4-\theta^{2}} \mu_{1}$ \\
\hline$\mu_{0}$ & 0 & $\frac{\left(a-y_{1}-\theta y_{2}\right)\left(y_{1}-\mu_{1}\right)}{3} \bar{z}$ & $\frac{\left(a-y_{1}-\theta y_{2}\right)\left(y_{1}-\mu_{1}\right)}{2} \bar{z}$ \\
\hline$\mu_{1}$ & $\frac{\frac{2-\theta}{4-\theta^{2}} a \sigma_{z}^{2}}{\frac{2-\theta^{2}}{4-\theta^{2}} \sigma_{z}^{2}+2 \sigma_{\varepsilon}^{2}}=a k_{1}$ & $\frac{\frac{2-\theta}{4-\theta^{2}} a \sigma_{z}^{2}}{\frac{2-\theta^{2}}{4-\theta^{2}} \sigma_{z}^{2}+3 \sigma_{\varepsilon}^{2}}=a k_{2}$ & $\frac{\frac{2-\theta}{4-\theta^{2}} a \sigma_{z}^{2}}{\frac{2-\theta^{2}}{4-\theta^{2}} \sigma_{z}^{2}+4 \sigma_{\varepsilon}^{2}}=a k_{3}$ \\
\hline$\mu_{2}$ & $\frac{a^{2} \sigma_{\varepsilon} \sqrt{l_{1}^{3} k_{1}}}{\sqrt{2} \sigma_{u}}$ & $\frac{\sqrt{2} a^{2} \sigma_{\varepsilon} \sqrt{l_{2}^{3} k_{2}}}{\sqrt{3} \sigma_{u}}$ & $\frac{\sqrt{3} a^{2} \sigma_{\varepsilon} \sqrt{l_{3}^{3} k_{3}}}{2 \sigma_{u}}$ \\
\hline$k$ & $k_{1}=\frac{\frac{2-\theta}{4-\theta^{2}} \sigma_{z}^{2}}{\frac{2-\theta^{2}}{4-\theta^{2}} \sigma_{z}^{2}+2 \sigma_{\varepsilon}^{2}}$ & $k_{2}=\frac{\frac{2-\theta}{4-\theta^{2}} \sigma_{z}^{2}}{\frac{2-\theta^{2}}{4-\theta^{2}} \sigma_{z}^{2}+3 \sigma_{\varepsilon}^{2}}$, & $k_{3}=\frac{\frac{2-\theta}{4-\theta^{2}} \sigma_{z}^{2}}{\frac{2-\theta^{2}}{4-\theta^{2}} \sigma_{z}^{2}+4 \sigma_{\varepsilon}^{2}}$, \\
\hline$l$ & $l_{1}=\frac{2-\theta}{4-\theta^{2}}+\frac{\theta^{2}-2}{4-\theta^{2}} k_{1}$ & $l_{2}=\frac{2-\theta}{4-\theta^{2}}+\frac{\theta^{2}-2}{4-\theta^{2}} k_{2}$ & $l_{3}=\frac{2-\theta}{4-\theta^{2}}+\frac{\theta^{2}-2}{4-\theta^{2}} k_{3}$ \\
\hline$B$ & $\frac{l_{1}^{2} a^{2}}{2} \bar{z}$ & $\frac{l_{2}^{2} a^{2}}{3} \bar{z}$ & $\frac{l_{3}^{2} a^{2}}{4} \bar{z}$ \\
\hline$\tilde{x}_{1}$ & $\frac{\sigma_{u}}{\sigma_{z}} \tilde{z}$ & $\frac{\sqrt{2}}{2} \frac{\sigma_{u}}{\sigma_{z}} \tilde{z}$ & $\frac{\sqrt{3}}{3} \frac{\sigma_{u}}{\sigma_{z}} \tilde{z}$ \\
\hline$\tilde{x}_{1}$ & $\frac{\sigma_{u} \sqrt{l_{1}}}{\sqrt{2} \sigma_{\varepsilon} \sqrt{k_{1}}} \tilde{z}$ & $\frac{\sigma_{u} \sqrt{l_{2}}}{\sqrt{6} \sigma_{\varepsilon} \sqrt{k_{2}}} \tilde{z}$ & $\frac{\sigma_{u} \sqrt{l_{3}}}{2 \sqrt{3} \sigma_{\varepsilon} \sqrt{k_{3}}} \tilde{z}$ \\
\hline$\tilde{x}_{2}$ & & $\frac{\sqrt{2}}{2} \frac{\sigma_{u}}{\sigma_{z}}(\tilde{z}-\bar{z})$ & $\frac{2 \sqrt{3}}{3} \frac{\sigma_{u}}{\sigma_{z}}(\tilde{z}-\bar{z})$ \\
\hline$\tilde{x}_{2}$ & & $\frac{\sigma_{u} \sqrt{l_{2}}}{\sqrt{6} \sigma_{\varepsilon} \sqrt{k_{2}}}(\tilde{z}-\bar{z})$ & $\frac{\sigma_{u} \sqrt{l_{3}}}{\sqrt{3} \sigma_{\varepsilon} \sqrt{k_{3}}}(\tilde{z}-\bar{z})$ \\
\hline $\operatorname{Var}(\tilde{z} \mid \tilde{q}, \tilde{r})$ & $\frac{\sigma_{\varepsilon}^{2}}{\sigma_{z}^{2}+2 \sigma_{\varepsilon}^{2}} \sigma_{z}^{2}$ & $\frac{\sigma_{\varepsilon}^{2}}{\sigma_{z}^{2}+3 \sigma_{\varepsilon}^{2}} \sigma_{z}^{2}$ & $\frac{\sigma_{\varepsilon}^{2}}{\sigma_{z}^{2}+4 \sigma_{\varepsilon}^{2}} \sigma_{z}^{2}$ \\
\hline$\pi_{1}(\tilde{z})$ & $\frac{2 \sigma_{u} \sigma_{\varepsilon}^{4} \mu_{1}^{2} \tilde{z}^{2}}{\sigma_{z}^{5}}$ & $\frac{3 \sqrt{2} \sigma_{u} \sigma_{\varepsilon}^{4} \mu_{1}^{2} \tilde{z}^{2}}{2 \sigma_{z}^{5}}$ & $\frac{4 \sqrt{3} \sigma_{u} \sigma_{\varepsilon}^{4} \mu_{1}^{2} \tilde{z}^{2}}{3 \sigma_{z}^{5}}$ \\
\hline$\pi_{1}(\tilde{z})$ & $\frac{2 \sigma_{u} \mu_{1}^{2} \tilde{z}^{2}}{\alpha^{2} \sigma_{z}}$ & $\frac{3 \sqrt{2} \sigma_{u} \mu_{1}^{2} \tilde{z}^{2}}{2 \alpha^{2} \sigma_{z}}$ & $\frac{4 \sqrt{3} \sigma_{u} \mu_{1}^{2} \tilde{z}^{2}}{3 \alpha^{2} \sigma_{z}}$ \\
\hline$\pi_{2}(\tilde{z})$ & & $\frac{3 \sqrt{2} \sigma_{u} \sigma_{\varepsilon}^{4} \mu_{1}^{2}(\tilde{z}-\bar{z})^{2}}{2 \sigma_{z}^{5}}$ & $\frac{8 \sqrt{3} \sigma_{u} \sigma_{\varepsilon}^{4} \mu_{1}^{2}(\tilde{z}-\bar{z})^{2}}{3 \sigma_{z}^{5}}$ \\
\hline$\pi_{2}(\tilde{z})$ & & $\frac{3 \sqrt{2} \sigma_{u} \mu_{1}^{2}(\tilde{z}-\bar{z})^{2}}{2 \alpha^{2} \sigma_{z}}$ & $\frac{8 \sqrt{3} \sigma_{u} \mu_{1}^{2}(\tilde{z}-\bar{z})^{2}}{3 \alpha^{2} \sigma_{z}}$ \\
\hline
\end{tabular}


Third, since real outputs are deterministic, the value of firm 1 is also a normal random variable. The normality of these random variables allows us to derive an explicit linear form for their conditional expected values. Hence, the stock price set by the market makers, which satisfies the zero expected profits condition, is linear. We present all the equilibrium outcomes in Table 1. Proofs are delegated to Appendices A, B and C. The second order conditions for the manager are,

$$
2 x_{1}(\tilde{z}) \tilde{z}>0 \text { and } \mu_{2}>0
$$

and the Hessian determinant is positive. The first condition in (13) is not always satisfied since the support of the normal random variables is the entire real line. Specifically, substituting the value of $x_{1}$ from (11) in the left hand condition in (13), we find,

$$
\frac{\left(a-y_{1}-\theta y_{2}\right)\left(y_{1}-\mu_{1}\right) \tilde{z}-\mu_{0}}{\mu_{2}} \tilde{z}>0 .
$$

Since the second order condition in (14) is quadratic, there exits values of $\tilde{z}$ for which the second order condition is not satisfied. Now, we present a necessary and sufficient condition for the existence of the linear equilibrium for all $\tilde{z}$.

Proposition 1 A linear equilibrium exists if and only if,

$$
\mu_{0}=B_{2}=\frac{\left(a-y_{1}-\theta y_{2}\right)\left(y_{1}-\mu_{1}\right)}{3} \bar{z} .
$$

Proof: See Daher and Mirman (2006).

\section{Discussion of the equilibrium}

Before interpreting the results, let us highlight the relationship between our three models and Jain and Mirman (2000, 2002), Daher and Mirman (2006, 2007), Wang et al. (2009) and Daher et al. (2012). Recall that odel 1 studies product differentiation in the real sector together with a monopoly structure in the financial sector. Model 2 extends Model 1 to incorporate Cournot competition in the financial sector. Finally, Model 3 extends Model 1 to include Stackelberg competition in the financial sector. First of all, note 
that Model 1 generalizes Jain and Mirman $(2000,2002) .{ }^{7}$ Indeed, Jain and Mirman (2000) corresponds to the case where $\theta=0$, while Jain and Mirman (2002) corresponds to the case where $\theta=1$. Similarly, Daher and Mirman (2007) is obtained when we take $\theta=0$ in Model 2, where we add a second insider to Model 1. Daher and Mirman (2006) corresponds to the case where $\theta=1$ in Model 2. Finally, Model 3 generalizes Daher et al. (2012) and Wang et al. (2009). The case where $\theta=0$ leads to Daher et al. (2012) while the case where $\theta=1$ corresponds to Wang et al. (2009). In sum, our paper generalizes the benchmark model of Jain and Mirman (2000) and almost ${ }^{8}$ all the subsequent papers.

For this purpose, we decide to divide the comparative statics of this paper into two parts. In the first part, we extend the results obtained in the two particular cases where $\theta=0$ and $\theta=1$ to the case $\theta \in(0,1)$. In the second part, we highlight the role of the real market structure adopted in our three models and its effect on the equilibrium outcomes. In other words, we study the impact of the product differentiation parameter $\theta$ on our equilibrium outcomes.

\subsection{Part I: Extended results}

Table 1 displays the equation of the market makers' response to the real signal coefficient $\mu_{1}$ in the three financial structures. First, note that $\mu_{1}$ in the monopoly case (Model 1 ) is greater than $\mu_{1}$ in the duopoly case (Model 2) which itself is greater than $\mu_{1}$ in the Stackelberg case (Model 3). This relation holds regardless of the degree of product differentiation $(\theta)$ and thus is consistent with the literature. For example, Daher and Mirman (2007) studied Cournot competition in the financial sector and monopoly in the real sector. They found that $\mu_{1}$ is lower than in Jain and Mirman (2000) that model a monopoly structure in both the real and financial sectors. Moreover, Wang et al. (2009) who modeled Stackelberg competition in the financial sector together with Cournot competition in the real sector, showed that $\mu_{1}$ is lower than in the duopoly structure in both the real and financial markets, as studied by Daher and Mirman (2006). Daher et al. (2011) considered the case of a monopoly structure in the real sector and Stackelberg competition in the financial market. They also obtained a lower value for $\mu_{1}$ compared to

\footnotetext{
${ }^{7}$ Without loss of generality and for the sake of simplicity, the inverse demand slope, $b$ , used in the literature, is assumed to be equal to one in this paper.

${ }^{8}$ Note that Wang and Wang (2010) studied a Stackelberg competition in the real market while Karam and Daher (2011) studied a two-tier real market structure and thus extended Jain and Mirman (2000) in different directions.
} 
the monopoly case in the real market studied by Jain and Mirman (2000) and Daher and Mirman (2007). To better understand this result, the expressions of $\mu_{1}$ presented in Table 1 are given by

$$
\mu_{1}^{1}=\frac{\frac{2-\theta}{4-\theta^{2}} a \sigma_{z}^{2}}{\frac{2-\theta^{2}}{4-\theta^{2}} \sigma_{z}^{2}+2 \sigma_{\varepsilon}^{2}}, \quad \mu_{1}^{2}=\frac{\frac{2-\theta}{4-\theta^{2}} a \sigma_{z}^{2}}{\frac{2-\theta^{2}}{4-\theta^{2}} \sigma_{z}^{2}+3 \sigma_{\varepsilon}^{2}}, \quad \mu_{1}^{3}=\frac{\frac{2-\theta}{4-\theta^{2}} a \sigma_{z}^{2}}{\frac{2-\theta^{2}}{4-\theta^{2}} \sigma_{z}^{2}+4 \sigma_{\varepsilon}^{2}}
$$

where $\mu_{1}^{i}$ is the expression of $\mu_{1}$ in Model $i(i=1,2,3)$. Notice that, the main difference between these expressions is captured by the coefficient of the variance of the noise signal $\sigma_{\varepsilon}^{2}$ in the denominator. The change of this coefficient is due to the structure adopted in the financial market. The total order flow signal is given by,

$$
\tilde{r}=\beta+\gamma \tilde{z}+\tilde{u},
$$

where the noise term $\tilde{u}$ in the total order flow signal is homoscedastic ${ }^{9}$. Hence, the greater the deterministic part $\gamma$ of the total order flow signal, the more informative the total order flow signal is and the greater the coefficient of the variance of the noise signal $\sigma_{\varepsilon}^{2}$ is. That is why the value of $\mu_{1}$ decreases in Model 2 with respect to the monopoly case in Model 1. Similarly, Stackelberg competition increases the total order flow signal ${ }^{10}$ with respect to the Cournot case and thus decreases the value of $\mu_{1}$ in Model 3. These results reflect the fact the total order flow signal reveals more information with Stackelberg competition in the financial sector than with Cournot competition, and more information with Cournot competition with respect to the monopoly case. Thus, the value of $\mu_{1}$ decreases when we go from monopoly to duopoly or from duopoly to Stackelberg.

Second, the expressions of firm 1's output displayed in Table 1 reveal a positive relation between $y_{1}$ and $\mu_{1}$. Consequently, firm 1's output $y_{1}$ in the monopoly case is greater than $y_{1}$ in the duopoly case which itself is greater than $y_{1}$ in the Stackelberg case. By contrast, there exists a negative relation between $y_{2}$ and $\mu_{1}$. Thus, firm 2's output $y_{2}$ in the monopoly case is lower than the duopoly case which itself is lower than the Stackerlberg case. Note that the degree of product differentiation $\theta$ does not alter the effect of the financial structure on the firms' output. The same conclusion is reached when we compare Daher and Mirmam (2006) with Jain and Mirman (2002), and Wang et al. (2009) with Daher and Mirman (2006). Recall that, the papers

\footnotetext{
${ }^{9}$ See Creane (1994).

${ }^{10}$ From Table 1 , the aggregate orders of the insiders in Model 2, $\tilde{x}_{1}+\tilde{x}_{2}$ is less than $\tilde{x}_{1}+\tilde{x}_{2}$ in Model 3 .
} 
mentioned above, all model Cournot duopoly in the real sector. However, the structure of the financial market differs between the three models. Jain and Mirman (2002) study a monopoly structure in the financial sector, Daher and Mirman (2006) model Cournot competition between the insiders and Wang et al. (2009) introduce Stackelberg competition in the financial sector.

Third, due to the negative relationship between the noise signal coefficient $\mu_{1}$ and the intercept coefficient $\mu_{0}$ (which results from the zero expected profits of the market maker), we infer that the value of $\mu_{0}$ in the Stackelberg case (Model 3) is greater than in the Cournot case (Model 2). Note that in the monopoly case the value of $\mu_{0}$, which results from the second order condition of the manager, is always less than the $\mu_{0}$ of the two other models.

Fourth, the financial market structure affects the revelation of information incorporated in the stock price. Indeed, Table 1 shows that under Stackelberg competition among the insiders, there is more information revealed in the stock price in the Cournot case. In turn, the stock price reveals more information with Cournot competition between the insiders than in the monopoly case. Recall that, the expression of the real signal is given by

$$
\tilde{q}=\left(a-y_{1}-\theta y_{2}\right)(\tilde{z}+\tilde{\varepsilon})
$$

while the total order flow signal is given by equation (15). Note that, the noise term $\tilde{u}$ in the total order flow signal is homoscedastic while the noise term $(\tilde{\varepsilon})$ in noise signal is heteroscedastic and multiplicative ${ }^{11}$, due to the deterministic distributions of the real variables (outputs). Consequently, any change in the financial market structure affects only the total order flow signal. Hence, the greater the deterministic part $\gamma$ of the total order flow signal, the more informative is the total order flow signal. Adding a second informed trader to the monopoly case (Model 2 ) or introducing Stackelberg competition between the two informed traders (Model 3), changes the values of the deterministic part of the total order flow signal. Such change alters the market makers' information about $z$ only through the total order flow signal.

Comparing the total order flow signal coefficients of Models 2 and 3, we find that $\gamma$ in Model 2 is greater than $\gamma$ in Model $1^{12}$. Consequently, adding Stackelberg competition in the financial sector increases the level of information

\footnotetext{
${ }^{11}$ See Creane (1994)

${ }^{12}$ Indeed, from Table 1 , we infer that $\tilde{x}=\tilde{x}_{1}+\tilde{x}_{2}$ in Model 2 is greater than $\tilde{x}=\tilde{x}_{1}+\tilde{x}_{2}$ in Model 3.
} 
incorporated in the stock price set by the market makers with respect to the Cournot case. Similarly, with Cournot competition in the financial sector, there is more information revealed in the stock price than in the monopoly case.

Moreover, it is worth mentioning that the amount of information revealed in the stock price is independent of the degree of product differentiation $\theta$. In other words, for a specific financial market structure, monopoly for example, Table 1 shows that the same amount of information is revealed in the stock price for any value of $\theta \in[0,1]$. This is due to the deterministic distributions of the real decision variables (outputs). Consequently, any change in such variables has no effect of the revelation of information.

Note that, the trading orders of the insiders are affected by the financial market structure. In line with the industrial organization theory, the manager's orders in the monopoly case (Model 1) are greater than his orders in the duopoly case (Model 2) which themselves are greater than in the Stackelberg case (Model 3). Moreover, in Model 3 and due to his leadership role in the financial market, the owner's orders are greater under Stackelberg competition than his orders under Cournot competition. It should be pointed out that surprisingly, all insiders' orders do not depend entirely on the real market structure and thus are independent of the degree of product differentiation $\theta$.

Finally, we comment on the owner's profits relation with the real market structure. The owner in the financial Stackelberg case acts as a leader and thus has a strategic advantage to the owner in the Cournot case. Consequently, he earns more profits when Stackelberg structure is adopted in the financial market than in Cournot case and this is independent of the real market.

\subsection{Part II: Product Differentiation Effects}

In the previous section, we extended the results of almost all equilibrium variables from the case $\theta=0$ and $\theta=1$ to the case where $\theta \in(0,1)$. It remains three variables whose comparative statics change with the real market structure. Specifically, from Table 1, we infer that the degree of differentiation $\theta$ and the ratio of the exogenous variances $\alpha=\frac{\sigma_{z}^{2}}{\sigma_{\varepsilon}^{2}}$ are the determinants of the product differentiation effect on the market makers' response to the total order flow, $\mu_{2}$, the compensation scheme received by the manager, $B$, and the managers profits, $\tilde{\pi}$. 


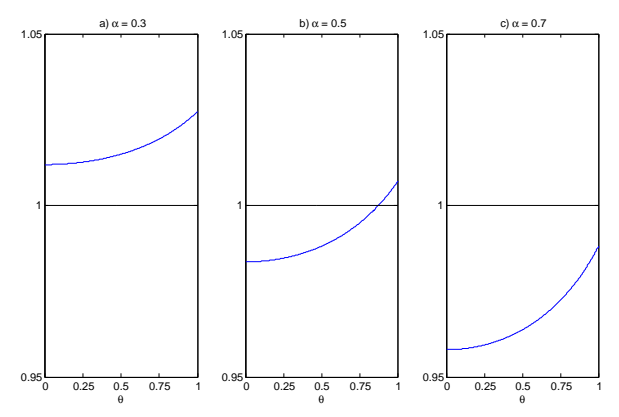

Figure 1: $\frac{\mu_{2}^{1}}{\mu_{2}^{2}}$ Ratio of the market maker's response to the total order flow of Models 1 and 2

\subsubsection{The market makers' response to the total order flow}

We analyze the product differentiation effect on the market makers' response to the total order flow, $\mu_{2}$. We computed in Appendix D the ratio (and its properties) of $\mu_{2}$ in any two different models. The calculations reveal the existence of a lower bound $\underline{\alpha}$ and an upper bound $\bar{\alpha}$ such that, for all the values of $\alpha$ that do not belong to the interval $(\underline{\alpha}, \bar{\alpha})$ (see Figure 1 ), the ratio is independent from the real market structure. In other words, the ratio is either greater than one (for $\alpha \leq \underline{\alpha}$ ) or less than one (for $\alpha \geq \bar{\alpha}$ ). However, for the values of $\alpha$ inside the interval, the real market structure through the degree of differentiation $\theta$, determines the level of the compensation earned by the manager.

Figure 1 provides the values of the $\mu_{2}$ 's ratio of Models 1 and 2 corresponding to three different values of $\alpha$. The value of $\underline{\alpha}$ corresponding to this case is 0.38 and $\bar{\alpha}=0.57$. Figure 1 -a shows that when $\alpha=0.3$ (less than $\underline{\alpha}=0.38$ ) the ratio is always greater than one, regardless of the real market structure. 
In other words, the value of $\mu_{2}$ in the monopolistic financial market is higher than $\mu_{2}$ in the presence of Cournot competition between the insiders. Indeed, when $\alpha$ is getting lower, the real signal becomes more noisy and thus less informative for the market marker. The expected value of firm 1 in both the monopolistic and the Cournot competition models is given by

$$
\left(a-y_{2}-\theta y_{1}\right) y_{2} \bar{z}-B_{2}
$$

When $\alpha$ is getting lower, the expected value of firm 1 in the monopolistic case becomes close to the expected value of firm 1 in the duopoly case. In this case, the result is similar to the Kyle (1985) type models, that is, the coefficient of the order flow decreases as the number of insiders increases and the value of the firm is the same (see Tighe 1989).

In Figure 1-b, we plot the ratio of $\mu_{2}$ of Models 1 and 2 when $\alpha=0.5$ (between the lower and upper bounds $\underline{\alpha}$ and $\bar{\alpha}$ ). For this value of $\alpha$, there exists a level of differentiation degree $\theta^{*}=0.8$ below which $\mu_{2}$ is greater in the presence of Cournot competition in the financial market than in the presence of a monopoly structure in the financial market. However, for the values of $\theta$ greater than 0.8 , the inverse holds, i.e. $\mu_{2}$ in the monopolistic financial market is greater than $\mu_{2}$ in the Cournot financial market. To understand the result, we recall the expressions of the unconditional profits of firm 1 in the monopoly and duopoly cases respectively derived from the zero profit condition of the market maker.

$$
\begin{gathered}
\left(a-y_{2}^{m}-\theta y_{1}^{m}\right) y_{2}^{m} \bar{z}-B_{1}=\mu_{1}^{m} \bar{q}^{m}+\mu_{2}^{m} \bar{r}^{m} \\
\left(a-y_{2}^{d}-\theta y_{1}^{d}\right) y_{2}^{d} \bar{z}-B_{2}=\mu_{1}^{d} \bar{q}^{d}+\mu_{2}^{d} \bar{r}^{d}
\end{gathered}
$$

where the superscripts $m$ and $d$ refer to monopoly and duopoly respectively. When $\alpha \in(\underline{\alpha}$ and $\bar{\alpha})$ and $\theta<\theta^{*}$, the left hand side of Eqs (18) and (19) are close in value and thus the right hand side must be close. In this case, $\mu_{2}$ in the monopolistic case is greater than $\mu_{2}$ in the duopoly case. For $\theta>\theta^{*}$, the unconditional profits of firm 1 in the monopolistic case in lower than in the duopoly case. Thus, the zero expected profit condition provides that $\mu_{2}$ in the duopoly case is greater than $\mu_{2}$ in the monopoly case.

Figure 1-c shows that for $\alpha=0.7>\alpha^{*}=0.57$, the value of $\mu_{2}$ in the financial duopoly case is greater than $\mu_{2}$ in the monopoly case (the ratio is greater than one) and this is regardless of the market structure adopted in the real market (for all values of $\theta$ ). For this value of $\alpha$, the left hand side of (18) 
is always less than the left hand side of (19). Hence, the right hand side of (18) must be less than the right hand side of (19). Such increase in profits going from the monopoly to the duopoly structure in the financial market, given that $\mu_{1}$ decreases more in the duopoly case than in the monopoly case, implies that the more informative signal be given more weight, thus $\mu_{2}$ in the duopoly case is greater than $\mu_{2}$ in the monopoly case.

Finally, it should be pointed out that, the analysis we provided in studying the comparative statics between Models 1 and 2 is applicable for the study of Models 1 and 3 or Models 2 and 3. For example, when $\alpha<\underline{\alpha}$ and going from duopoly to Stackelberg in the financial market, $\mu_{2}$ in the duopoly becomes greater than $\mu_{2}$ in Stackelberg. The reason is the same as in the study we did for Models 1 and 2, i.e. for this value of $\alpha$, the real signal becomes less informative and the unconditional profits of firm 1 in both the duopoly and Stackelberg cases are close. Thus, the model resembles to the Kyle-type models with the same value of the firm, that is the coefficient of the order flow decreases when we go from duopoly to Stackelberg in the financial market (see Daher et al. 2012).

\subsubsection{Compensation Scheme}

We turn now to analyze the product differentiation effect on the compensation scheme received by the manager in each of the models studied in the paper. We computed in Appendix E the ratio (and its properties) of the compensation scheme for any two different models. There exists a lower bound $\underline{\alpha}$ and an upper bound $\bar{\alpha}$ such that, for all the values of $\alpha$ that do not belong to the interval $(\underline{\alpha}, \bar{\alpha})$ (see Figure 2 ), the ratio is independent from the real market structure. In other words, the ratio is either greater than 1 (for $\alpha \leq \underline{\alpha}$ ) or less than 1 (for $\alpha \geq \bar{\alpha}$ ). However, for the values of $\alpha$ inside the interval, the real market structure through the degree of differentiation, $\theta$, determines the level of the compensation earned by the manager.

Figure 2 provides values of the compensation scheme ratio of Models 1 and 2 corresponding to three different values of $\alpha$. The value of $\underline{\alpha}$ corresponding to this case is $2 \sqrt{6}$ and $\bar{\alpha}=3 \sqrt{6}$. Figure 2-a shows that when $\alpha=4$ (less than $\underline{\alpha}=2 \sqrt{6}$ ), the ratio is always greater than one, regardless of the real market structure. In other words, the compensation scheme of the manager in the monopolistic financial market is higher that his compensation in the presence of Cournot competition between the insiders. Indeed, when $\alpha$ is getting lower, the real signal becomes more noisy and thus less informative 


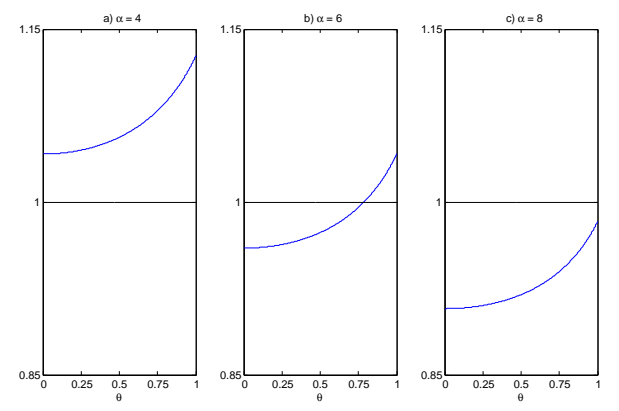

Figure 2: $\frac{B_{1}}{B_{2}}$ Ratio of the compensation scheme of Models 1 and 2

for the market marker. Hence, the manager of the firm profits from this opportunity to earn a higher compensation than in the Cournot case where he does not have market power due to the presence of the second insider (the owner).

To understand this relationship between the exogenous variances, the degree of differentiation and the compensation scheme of the manager, recall the expression of the compensation scheme of each of the models (see Table 1):

$$
B_{1}=\frac{l_{1}^{2} a^{2}}{2} \bar{z}, \quad B_{2}=\frac{l_{2}^{2} a^{2}}{3} \bar{z}, \quad B_{3}=\frac{l_{3}^{2} a^{2}}{4} \bar{z}
$$

First, note that we showed in Appendix $\mathrm{C}$ that $l_{1}<l_{2}<l_{3}$ and this relation is independent of the exogenous variances and the degree of differentiation. Second, the financial market structure determines the value of the denominator in the compensation scheme expressions. For example, in the financial monopolistic case, the denominator is two. However, in the duopoly case it becomes three. Thus, the comparison of the compensation schemes in Models 1 and 2 for example, is based on the relation between $\frac{l_{1}}{2}$ and $\frac{l_{2}}{3}$. Note 
that, when $\alpha$ is less than $\underline{\alpha}$, the expressions of $l_{1}$ and $l_{2}$ are close to each other and consequently the compensation scheme in the financial Cournot case is lower than in the financial monopoly case.

In Figure 2-b, we plot the ratio of the compensation scheme of Models 1 and 2 when $\alpha=6$ (between the lower and upper bounds $\underline{\alpha}$ and $\bar{\alpha}$ ). For this value of $\alpha$, there exists a level of differentiation degree $\theta^{*}=0.75$ below which the manager earns more compensation in the presence of Cournot competition in the financial market than in the presence of a monopoly structure in the financial market. However, for the values of $\theta$ greater than 0.75 , the inverse holds, i.e., in the monopolistic financial market, the manager earns more compensation than in the Cournot financial market.

For $\alpha \in(\underline{\alpha}, \bar{\alpha})$, the relation between $\frac{l_{1}}{2}$ and $\frac{l_{2}}{3}$ depends on the degree of differentiation. Indeed, when the goods are less substitutable, the manager earns more compensation under the financial Cournot competition than the monopolistic financial structure. However, when the goods are close substitutes to each others, the manager's compensation is higher in the monopolistic financial structure than the Cournot case.

For the last case, when $\alpha$ is greater than $\bar{\alpha}$, Figure 2-c shows that for $\alpha=8$, the ratio of the compensation schemes of Models 1 and 2 is always greater than one. In other words, the manager's compensation in the financial Cournot case is greater than his compensation in the financial monopoly case. In this case, the value of $l_{1}$ is relatively small compared to $l_{2}$ and thus the compensation scheme is the monopoly case is less than in the Cournot case.

\subsubsection{Manager's profits}

The manager's profits depend crucially on the exogenous variances and the real market structure. Indeed, as for the case of the compensation scheme, we distinguish three cases of relationship between the manager's profits in Models 1 and 2. In Appendix F, the ratio of the manager's profits of any two models is computed. There exist a lower bound $\underline{\alpha}$ and upper bound $\bar{\alpha}$ which characterize the relationship between the manager's profits in any two different models. Figure 3 displays the values of the manager's profits ratio for Models and 1 and 2 .

For $\alpha$ less than $\underline{\alpha}$ (Figure 3-a), the manager's profits in the monopolistic case 


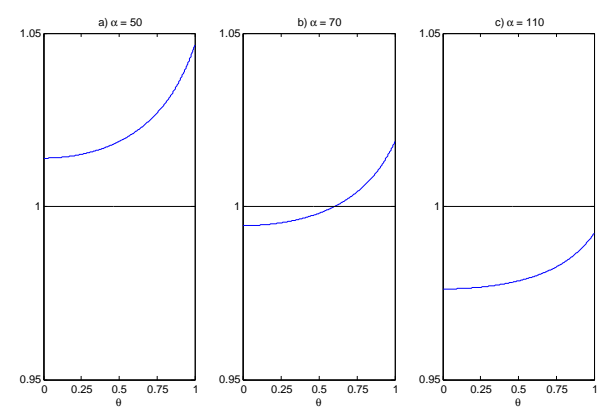

Figure $3: \frac{\pi_{1}^{1}}{\pi_{1}^{2}}$ Ratio of the compensation scheme of Models 1 and 2

are greater than in the Cournot case. From Table 1, the expressions of the manager's profits in the monopoly and duopoly cases, respectively are

$$
\frac{2 \sigma_{u} \sigma_{\varepsilon}^{4} \mu_{1}^{2} \tilde{z}^{2}}{\sigma_{z}^{5}} \quad \frac{3 \sqrt{2} \sigma_{u} \sigma_{\varepsilon}^{4} \mu_{1}^{2} \tilde{z}^{2}}{2 \sigma_{z}^{5}}
$$

Note that $2 \mu_{1}^{M}$ and $\frac{3 \sqrt{2}}{2} \mu_{1}^{D}$ determine the relationship of the manager's profits of Models 1 an 2. For $\alpha$ less than $\underline{\alpha}, 2 \mu_{1}^{M}$ is always greater than $\frac{3 \sqrt{2}}{2} \mu_{1}^{D}$ and thus the manager's profits are greater in the monopoly case than in the duopoly case. The intuition behind is that for such values of $\alpha$, increasing the number of insiders increases the informational content of the total order flow signal $\tilde{r}$ which in turn reduces the manager's profits in the duopoly case relative to the monopoly case.

For $\alpha \in(\underline{\alpha}, \bar{\alpha})$ (Figure 3-b), the real market structure determines the relationship of the manager's profits of Models 1 and 2. Indeed, there exists a level of differentiation $\theta^{*}$ below which the manager's profits under the monopoly case are less than in the Cournot case. However, when the real products become more substitutable $\left(\theta>\theta^{*}\right)$, the manager's profits in the monopoly case are greater than those in the Cournot case. In this case, the real signal 
$\tilde{q}$ and the total order flow signal $\tilde{r}$ disseminate information to the market maker. Together with the real market structure have a direct effect on the unconditional profits of the manager through the zero profits condition of the market makers.

In the last case when $\alpha>\bar{\alpha}$ (Figure 3-c), the real market structure has no effect on the relationship of the manager's profits of Models 1 and 2. For such values of $\alpha$, the manager's profits in the financial Cournot case are always greater than in the monopoly case. Note that in this case, the real signal $\tilde{q}$ is more informative than the total order flow signal $\tilde{r}$. This informational content reduces the value of firm 1 in the monopoly case which in turn reduces the manager's profits in the monopoly case relative to the Cournot case.

It should be pointed out that when real decisions are made, going from one insider (Model 1) to two insiders (Model 2) has an ambiguous effect on the manager's profits. Indeed, Daher et al.(2012) extended Jain and Mirman (1999) to the Cournot case. In both models, no real market is considered. The authors show that going from one to two insiders, the manager's profits always decrease. However, with real decisions, the manager's profits depend on both the real and the financial structure.

\section{Appendix A}

We start this appendix by recalling the Theorem that we use to prove the results in Table 1.

Theorem 1 If the $p \times 1$ vector $Y$ is normally distributed with mean $U$ and covariance $V$ and if the vector $Y$ is partitioned into two subvectors such that $Y=\left(\begin{array}{c}Y_{1} \\ Y_{2}\end{array}\right)$ and if $Y^{*}=\left(\begin{array}{c}Y_{1} \\ Y_{2}^{*}\end{array}\right)$

$$
U=\left(\begin{array}{c}
U_{1} \\
U_{2}
\end{array}\right) \text { and } V=\left(\begin{array}{ll}
V_{11} & V_{12} \\
V_{21} & V_{22}
\end{array}\right)
$$

are the corresponding partitions of $Y^{*}, U$ and $V$, then the conditional distribution of the $m \times 1(m<p)$ vector $Y_{1}$ given the vector $Y_{2}=Y_{2}^{*}$ is the multivariate normal distribution with mean $U_{1}+V_{12} V_{22}^{-1}\left(Y_{2}^{*}-U_{2}\right)$ and covariance matrix $V_{11}-V_{12} V_{22}^{-1} V_{21}$.

Proof: See Graybill, Theorem 3.10 pp 63. 
We apply Theorem 1 to the normal random vector $B=(\tilde{v}, \tilde{q}, \tilde{r})$. First, in this case we have $p=3$ and $m=1$. Second, by identification, we have $Y_{1}=\tilde{v}$ and $Y_{2}=\left(\begin{array}{c}\tilde{q} \\ \tilde{r}\end{array}\right) \cdot U_{1}=\bar{v}, U_{2}=\left(\begin{array}{c}\bar{q} \\ \bar{r}\end{array}\right)$ and

$$
V=\left(\begin{array}{ccc}
\sigma_{v}^{2} & \sigma_{v q} & \sigma_{v r} \\
\sigma_{v q} & \sigma_{q}^{2} & \sigma_{q r} \\
\sigma_{v r} & \sigma_{q r} & \sigma_{r}^{2}
\end{array}\right)=\left(\begin{array}{cc}
V_{11} & V_{12} \\
V_{21} & V_{22}
\end{array}\right)
$$

where $V_{11}=\sigma_{v}^{2}, V_{12}=\left(\sigma_{v q}, \sigma_{v r}\right), V_{21}=\left(\begin{array}{c}\sigma_{v q} \\ \sigma_{v r}\end{array}\right)$ and $V_{22}=\left(\begin{array}{cc}\sigma_{q}^{2} & \sigma_{q r} \\ \sigma_{q r} & \sigma_{r}^{2}\end{array}\right)$.

Note that

$$
V_{22}^{-1}=\frac{1}{D}\left(\begin{array}{cc}
\sigma_{r}^{2} & -\sigma_{q r} \\
-\sigma_{q r} & \sigma_{q}^{2}
\end{array}\right)
$$

where $D$ is the determinant of $V_{22}$, that is $D=\sigma_{q}^{2} \sigma_{r}^{2}-\sigma_{q r}^{2}$.

So we obtain,

$$
\begin{aligned}
& \mu_{0}=\bar{v}-\mu_{1} \bar{q}-\mu_{2} \bar{r} \\
& \mu_{1}=\frac{\sigma_{v q} \sigma_{r}^{2}-\sigma_{v r} \sigma_{q r}}{D} \\
& \mu_{2}=\frac{\sigma_{v r} \sigma_{q}^{2}-\sigma_{v q} \sigma_{q r}}{D}
\end{aligned}
$$

We start now by computing all the covariances in the last two expressions. Indeed, we have

$$
\begin{gathered}
\sigma_{v q}=\left(a-y_{1}-\theta y_{2}\right)^{2} y_{1} \sigma_{z}^{2} \\
\sigma_{r}^{2}=\frac{\left(a-y_{1}-\theta y_{2}\right)^{2}\left(y_{1}-\mu_{1}\right)^{2}}{4 \mu_{2}^{2}} \sigma_{z}^{2}+\sigma_{u}^{2} \\
\sigma_{v r}=\frac{\left(a-y_{1}-\theta y_{2}\right)^{2}\left(y_{1}-\mu_{1}\right) y_{1}}{2 \mu_{2}} \sigma_{z}^{2} \\
\sigma_{q}^{2}=\left(a-y_{1}-\theta y_{2}\right)^{2}\left(\sigma_{z}^{2}+\sigma_{\varepsilon}^{2}\right) \\
\sigma_{q r}=\frac{\left(a-y_{1}-\theta y_{2}\right)^{2}\left(y_{1}-\mu_{1}\right)}{2 \mu_{2}} \sigma_{z}^{2}
\end{gathered}
$$


Substituting for the variances and covariances in (23) and (24), we get

$$
\begin{gathered}
\mu_{1}=\frac{\left(a-y_{1}-\theta y_{2}\right)^{2} y_{1} \sigma_{z}^{2} \sigma_{u}^{2}}{D}, \\
\mu_{2}=\frac{\left(a-y_{1}-\theta y_{2}\right)^{4} y_{1}\left(y_{1}-\mu_{1}\right) \sigma_{z}^{2} \sigma_{\varepsilon}^{2}}{\mu_{2} D} .
\end{gathered}
$$

Computing (25) and (26), we obtain

$$
\mu_{2}^{2}=\frac{\left(a-y_{1}-\theta y_{2}\right)^{2} \mu_{1}\left(y_{1}-\mu_{1}\right) \sigma_{\varepsilon}^{2}}{2 \sigma_{u}^{2}}
$$

Calculating for the expression of $D$, we get

$$
D=\frac{\left(a-y_{1}-\theta y_{2}\right)^{4}\left(y_{1}-\mu_{1}\right)^{2} \sigma_{\varepsilon}^{2} \sigma_{z}^{2}}{4 \mu_{2}^{2}}+\left(a-y_{1}-\theta y_{2}\right)^{2} \sigma_{u}^{2}\left(\sigma_{\varepsilon}^{2}+\sigma_{z}^{2}\right) .
$$

Substituting the above expression of $D$ in (26), we find

$$
\mu_{2}^{2}=\frac{\left(a-y_{1}-\theta y_{2}\right)^{2}\left(y_{1}-\mu_{1}\right)\left(y_{1}+\mu_{1}\right) \sigma_{\varepsilon}^{2} \sigma_{z}^{2}}{4 \sigma_{u}^{2}\left(\sigma_{\varepsilon}^{2}+\sigma_{z}^{2}\right)} .
$$

Solving (27) and (28), we get

$$
2 \mu_{1}\left(\sigma_{\varepsilon}^{2}+\sigma_{z}^{2}\right)=\sigma_{z}^{2}\left(y_{1}+\mu_{1}\right) .
$$

Substituting for $y$ to solve $\mu_{1}$, we obtain

$$
\mu_{1}=\frac{\frac{2-\theta}{4-\theta^{2}} a \sigma_{z}^{2}}{\frac{2-\theta^{2}}{4-\theta^{2}} \sigma_{z}^{2}+2 \sigma_{\varepsilon}^{2}}
$$

To solve for $\mu_{2}$, we substitute the above value of $\mu_{1}$ in (27) and taking the positive root, we get

$$
\mu_{2}=\frac{a^{2} \sigma_{\varepsilon} \sqrt{l^{3} k}}{\sqrt{2} \sigma_{u}}
$$

where $k=\frac{\frac{2-\theta}{4-\theta^{2}} \sigma_{z}^{2}}{\frac{2-\theta^{2}}{4-\theta^{2}} \sigma_{z}^{2}+2 \sigma_{\varepsilon}^{2}}$ and $l=\frac{2-\theta}{4-\theta^{2}}+\frac{\theta^{2}-2}{4-\theta^{2}} k$ 


\section{Appendix B}

Here, the main change with respect to appendix $\mathrm{A}$ is the reaction curves derivation of each insider. Indeed, the owner first decides the stock order $x_{2}(\tilde{z})$ and second the manager of firm 1, chooses the output $y_{1}$ as well as his order $x_{1}(\tilde{z})$. Proceeding backward by solving first the manager's problem and then the owner's maximization problem, the manager moves second and hence his reaction curve is given by

$$
x_{1}(\tilde{z})=\frac{\left(a-y_{1}-\theta y_{2}\right)\left(y_{1}-\mu_{1}\right) \tilde{z}-\mu_{0}-\mu_{2} \tilde{x_{2}}}{2 \mu_{2}}
$$

Now plugging (31) into the profit function of the owner and taking the first order condition we find,

$$
\tilde{x}_{2}=\frac{\left(a-y_{1}-\theta y_{2}\right)\left(y_{1}-\mu_{1}\right) \tilde{z}-\mu_{0}-2 B_{3}}{2 \mu_{2}}
$$

which implies that

$$
\tilde{x}_{1}=\frac{\left(a-y_{1}-\theta y_{2}\right)\left(y_{1}-\mu_{1}\right) \tilde{z}-\mu_{0}+2 B_{3}}{4 \mu_{2}}
$$

\section{Appendix $\mathrm{C}$}

We show that the value of $l$ is always positive in the three models studied in this paper. First, one can remark that (after arrangement) that

$$
l_{1} \leq l_{2} \text { and } l_{1} \leq l_{3}
$$

where $l_{i}$ is the expression of $l$ corresponding to Model $i(i=1,2,3)$. Hence, if we show that $l_{1}$ is positive, then $l_{2}$ and $l_{3}$ are also positive. Indeed, recall that

$$
k_{1}=\frac{\frac{2-\theta}{4-\theta^{2}} \sigma_{z}^{2}}{\frac{2-\theta^{2}}{4-\theta^{2}} \sigma_{z}^{2}+2 \sigma_{\varepsilon}^{2}} \text { and } l_{1}=\frac{2-\theta}{4-\theta^{2}}+\frac{\theta^{2}-2}{4-\theta^{2}} k
$$

Now, we define $\alpha=\frac{\sigma_{z}^{2}}{\sigma_{\varepsilon}^{2}}$. Hence equation (34) becomes

$$
k_{1}=\frac{(2-\theta) \alpha}{\left(2-\theta^{2}\right) \alpha+2\left(4-\theta^{2}\right)} \text { and } l_{1}=\frac{2-\theta+\left(\theta^{2}-2\right) k}{4-\theta^{2}}
$$

Since $\theta \in[0,1]$ proving that $l_{1}$ is equivalent to prove that

$$
2-\theta+\left(\theta^{2}-2\right) k_{1} \geq 0
$$


Substituting the expression of $k_{1}$ from (35) into the expression in (36) and using the fact that $\theta \in[0,1]$, we deduce that $2-\theta+\left(\theta^{2}-2\right) k_{1} \geq 0$ and hence $l_{1}$ is always positive.

\section{Appendix D}

We compute the ratio of the market marker's response to the order flow signal of any two models studied in this paper. From Table 1 note that,

$$
\frac{\mu_{2}^{i}}{\mu_{2}^{j}}=\frac{\sqrt{i}}{\sqrt{j}} \frac{i+1}{j+1} \cdot\left(\frac{\left(2-\theta^{2}\right) \alpha+(j+1)\left(4-\theta^{2}\right)}{\left(2-\theta^{2}\right) \alpha+(i+1)\left(4-\theta^{2}\right)}\right)^{2}, \alpha=\frac{\sigma_{z}^{2}}{\sigma_{\varepsilon}^{2}}, i \neq j .
$$

Without loss of generality, assume that $i<j$ and consider the two following cases:

Case 1: $\alpha \rightarrow 0$. In this case $\frac{\mu_{2}^{i}}{\mu_{2}^{j}} \rightarrow \frac{\sqrt{i}}{\sqrt{j}} \frac{j+1}{i+1}>1$

Case 2: $\alpha \rightarrow \infty$. In this case $\frac{\mu_{2}^{i}}{\mu_{2}^{j}} \rightarrow \frac{\sqrt{i}}{\sqrt{j}} \frac{i+1}{j+1}<1$

Hence, we deduce that $\frac{\mu_{2}^{i}}{\mu_{2}^{j}} \in\left(\frac{\sqrt{i}}{\sqrt{j}} \frac{i+1}{j+1}, \frac{\sqrt{i}}{\sqrt{j}} \frac{j+1}{i+1}\right) \forall \alpha$ and $\theta$.

Moreover, note that $\frac{\mu_{2}^{i}}{\mu_{2}^{j}}$ is increasing in $\theta$ (its derivative is positive) and thus

there exist a lower bound denoted by $\underline{\alpha}=2 \sqrt{i+1} \sqrt{j+1} \frac{\sqrt[4]{i} \sqrt{j+1}-\sqrt{i+1} \sqrt[4]{j}}{\sqrt[4]{j} \sqrt{j+1}-\sqrt{i+1} \sqrt[4]{i}}$ (corresponding to $\theta=0$ ) and an upper bound denoted by $\bar{\alpha}=3 \sqrt{i+1} \sqrt{j+1} \frac{\sqrt[4]{i} \sqrt{j+1}-\sqrt{i+1} \sqrt[4]{j}}{\sqrt[4]{j} \sqrt{j+1}-\sqrt{i+1} \sqrt[4]{i}}($ corresponding to $\theta=1)$ such that (see Figure 1):

1- $\frac{\mu_{2}^{i}}{\mu_{2}^{j}}$ is always greater than 1 for all values $\alpha \leq \underline{\alpha}$ and for all values of $\theta$.

2- $\frac{\mu_{2}^{i}}{\mu_{2}^{j}}$ is always lower than 1 for all values $\alpha \geq \bar{\alpha}$ and for all values of $\theta$.

3- $\frac{\mu_{2}^{i}}{\mu_{2}^{j}}$ depends on $\theta$ when $\alpha \in(\underline{\alpha}, \bar{\alpha})$. 


\section{Appendix E}

In this appendix we compute the ratio of the compensation schemes of any two models studied in this paper. From Table 1 note that,

$$
\frac{B_{i}}{B_{j}}=\frac{j+1}{i+1} \cdot\left(\frac{l_{i}}{l_{j}}\right)^{2} \quad i \neq j, \quad i, j=1,2,3
$$

Substituting the corresponding expressions of $l_{i}$ and $l_{j}$ respectively from Table 1 into equation (38) we obtain

$$
\frac{B_{i}}{B_{j}}=\frac{i+1}{j+1} \cdot\left(\frac{\left(2-\theta^{2}\right) \alpha+(j+1)\left(4-\theta^{2}\right)}{\left(2-\theta^{2}\right) \alpha+(i+1)\left(4-\theta^{2}\right)}\right)^{2}, \alpha=\frac{\sigma_{z}^{2}}{\sigma_{\varepsilon}^{2}}, i \neq j .
$$

Without loss of generality, assume that $i<j$ and consider the two following cases:

Case 1: $\alpha \rightarrow 0$. In this case $\frac{B_{i}}{B_{j}} \rightarrow \frac{j+1}{i+1}>1$

Case 2: $\alpha \rightarrow \infty$. In this case $\frac{B_{i}}{B_{j}} \rightarrow \frac{i+1}{j+1}<1$

Hence, we deduce that $\frac{B_{i}}{B_{j}} \in\left(\frac{i+1}{j+1}, \frac{j+1}{i+1}\right) \forall \alpha$ and $\theta$.

Moreover, note that $\frac{B_{i}}{B_{j}}$ is increasing in $\theta$ (its derivative is positive) and thus there exist a lower bound denoted by $\underline{\alpha}=2 \sqrt{i+1} \sqrt{j+1}$ (corresponding to $\theta=0$ ) and an upper bound denoted by $\bar{\alpha}=3 \sqrt{i+1} \sqrt{j+1}$ (corresponding to $\theta=1$ ) such that (see Figure 2):

$1-\frac{B_{i}}{B_{j}}$ is always greater than 1 for all values $\alpha \leq \underline{\alpha}$ and for all values of $\theta$.

2- $\frac{B_{i}}{B_{j}}$ is always lower than 1 for all values $\alpha \geq \bar{\alpha}$ and for all values of $\theta$.

3- $\frac{B_{i}}{B_{j}}$ depends on $\theta$ when $\alpha \in(\underline{\alpha}, \bar{\alpha})$.

\section{Appendix F}

We derive The ratio of the manager's profits of any two models studied in this paper. From Table 1 note that,

$$
\frac{\pi_{1}^{i}}{\pi_{1}^{j}}=\frac{\sqrt{j}}{\sqrt{i}} \frac{i+1}{j+1} \cdot\left(\frac{\mu_{1}^{i}}{\mu_{j}^{i}}\right)^{2}, \quad i \neq j .
$$


Substituting the expressions of $\mu_{1}$ from Table 1 , we obtain

$$
\frac{\pi_{1}^{i}}{\pi_{1}^{j}}=\frac{\sqrt{j}}{\sqrt{i}} \frac{i+1}{j+1} \cdot\left(\frac{\left(2-\theta^{2}\right) \alpha+(j+1)\left(4-\theta^{2}\right)}{\left(2-\theta^{2}\right) \alpha+(i+1)\left(4-\theta^{2}\right)}\right)^{2}, \alpha=\frac{\sigma_{z}^{2}}{\sigma_{\varepsilon}^{2}}, i \neq j .
$$

Without loss of generality, assume that $i<j$ and consider the two following cases:

Case 1: $\alpha \rightarrow 0$. In this case $\frac{\pi_{1}^{i}}{\pi_{1}^{j}} \rightarrow \frac{\sqrt{j}}{\sqrt{i}} \frac{j+1}{i+1}>1$

Case 2: $\alpha \rightarrow \infty$. In this case $\frac{\pi_{1}^{i}}{\pi_{1}^{j}} \rightarrow \frac{\sqrt{j}}{\sqrt{i}} \frac{i+1}{j+1}<1$

Hence, we deduce that $\frac{\pi_{1}^{i}}{\pi_{1}^{j}} \in\left(\frac{\sqrt{j}}{\sqrt{i}} \frac{i+1}{j+1}, \frac{\sqrt{j}}{\sqrt{i}} \frac{j+1}{i+1}\right) \forall \alpha$ and $\theta$.

Moreover, note that $\frac{\pi_{1}^{i}}{\pi_{1}^{j}}$ is increasing in $\theta$ (its derivative is positive) and thus there exist a lower bound denoted by $\underline{\alpha}=2 \sqrt{i+1} \sqrt{j+1} \frac{\sqrt[4]{j} \sqrt{j+1}-\sqrt{i+1} \sqrt[4]{i}}{\sqrt[4]{i} \sqrt{j+1}-\sqrt{i+1} \sqrt[4]{j}}$ (corresponding to $\theta=0$ ) and an upper bound denoted by $\bar{\alpha}=3 \sqrt{i+1} \sqrt{j+1} \frac{\sqrt[4]{j} \sqrt{j+1}-\sqrt{i+1} \sqrt[4]{i}}{\sqrt[4]{i} \sqrt{j+1}-\sqrt{i+1} \sqrt[4]{j}}($ corresponding to $\theta=1)$ such that (see Figure 3):

$1-\frac{\pi_{1}^{i}}{\pi_{1}^{j}}$ is always greater than 1 for all values $\alpha \leq \underline{\alpha}$ and for all values of $\theta$.

2- $\frac{\pi_{1}^{i}}{\pi_{1}^{j}}$ is always lower than 1 for all values $\alpha \geq \bar{\alpha}$ and for all values of $\theta$.

3- $\frac{\pi_{1}^{i}}{\pi_{1}^{j}}$ depends on $\theta$ when $\alpha \in(\underline{\alpha}, \bar{\alpha})$.

\section{References}

[1] Anderson, S.P., de Palma, A. \& Thisse, J.F. Discrete Choice Theory of Product Differentiation, 1992, MIT Press, Cambridge, Mass.

[2] Beath, J. \& Katsoulacos, Y. The Economic Theory of Product Differentiation, 1991, Cambridge University Press.

[3] Berry, S.T. Estimating Discrete-Choice Models of Product Differentiation, The RAND Journal of Economics, 25(2), (1994), 242-262. 
[4] Caldentey, R. \& Stacchetti, E. Insider Trading with a Random Deadline, Econometrica, 78, (2010), 245-283.

[5] Chamberlin, E. The Theory of Monopolistic Competition, 1933, Cambridge: Harvard University Press.

[6] Cheng, L.T.W., Davidson III, W.N. \& Leung, T.Y. Insider Trading Returns and Dividend Signals, International Review of Economics and Finance, 20, (2011), 421-429.

[7] Creane, A. Experimentation with Heteroskedastic Noise, Economic Theory, 4, (1994), 275-286.

[8] Daher, W., Karam, F. \& Mirman, L.J. Insider Trading with Different Market Structures, The International Review of Economics and Finance. 24, (2012), 143-154.

[9] Daher, W. \& Mirman, L.J. Market Structure and Insider Trading, The International Review of Economics and Finance. 16, (2007), 306-331.

[10] Daher, W. \& Mirman, L.J. Cournot Duopoly and Insider Trading with Two Insiders, The Quarterly Review of Economics and Finance. 46, (2006), 530-551.

[11] Dow, J. \& Rahi, R. Informed Trading, Investment and Welfare, Journal of Business, 76, (2003), 439-454.

[12] Graybill, F. An Introduction to Linear Statistical Models: Volume I, McGraw Hill. 1961.

[13] Holden, C. \& Subrahmanyam, A. Long-Lived Private Information and Imperfect Competition, Journal of Finance. 47, (1992), $247-270$.

[14] Jain, N. \& Mirman, L.J. Real and Financial Effects of Insider Trading with Correlated Signals, Economic Theory. 16, (2000), 333-353.

[15] Jain, N. \& Mirman, L.J. Effects of Insider Trading under Different Market Structures, The Quarterly Review of Economics and Finance. 42, (2002), 19-39.

[16] Jain, N. \& Mirman, L.J. Insider Trading with Correlated Signals, Economics Letters. 65, (1999), 105-113. 
[17] Julien, L.A. A Note on Stackelberg Competition, Journal of Economics. 103, (2011), 171-187.

[18] Karam, F. \& Daher, W., Insider Trading in a Two-Tier Real Market Structure Model Documents de travail du Centre d'Economie de la Sorbonne, working paper 11068.

[19] Kyle, A. Continuous Auctions and Insider Trading, Econometrica. 53, (1985), 1315-1335.

[20] Leland, H.E. Insider Trading: Should it be Prohibited, Journal of Political Economy, 100, (1992), 859-887.

[21] Liang, W.L., Lin, H.W. \& Syu, Y.J. Precision of Investor Information and Financial Disclosure, International Review of Economics and Finance, 19(4), (2010), 627-632.

[22] Liu, H. \& Zhang Z. Insider Trading with Public and Shared Information, Economic Modelling, 28, (2011), 1756-1762.

[23] Manove, M. The Harm from Insider Trading and Informed Speculation, Quarterly Journal of Economics, 104,(1989), 823-845.

[24] Nevo, A. Identification of the Oligopoly Solution Concept in a Differentiated-Products Industry, Economics Letters, $\mathbf{5 9 , ( 1 9 9 8 ) , ~ 3 9 1 - 3 9 5 . ~}$

[25] O'Hara, M. "Market Microstructure Theory", Basil Blackwell, Cambridge, Mass. 1995.

[26] Rochet, J-C. \& Vila, J-L. Insider Trading without Normality, Review of Economic Studies, 61,(1994), 131-152.

[27] Shaked, A. \& Sutton, J. Relaxing Price Competition Through Product Differentiation, Review of Economic Studies, 49,(1982), 3-14.

[28] Shaked, A. \& Sutton, J. Natural Oligopolies, Econometrica, 51,(1983), 1469-1484..

[29] Shaked, A. \& Sutton, J. Product Differentiation and Industrial Structure, The Journal of Industrial Economics, 36(2),(1987), 131-146. 
[30] Sutton, J. Vertical Product Differentiation: Some Basic Themes, American Economic Review : papers and proceedings, 76(2), (1986), 393-398.

[31] Tighe, C.E. "Three Essays on Insider Trading" unpublished Ph.D dissertation, University of Illinois at Champaign-Urbana (1989).

[32] Tighe, C. \& Michener, R. The Political Economy of Insider Trading Laws, American Economic Review. 84, (1994), 164168.

[33] Wang, L.F.S, Wang, Y-C. \& Ren, S. Stackelberg FinancialLeader in Insider Trading Model, The International Review of Economics and Finance. 18, (2009), 123-131.

[34] Wang, L.F.S. \& Wang, Y-C. Stackelberg Real-Leader in an Insider Trading Model, Studies in Economics and Finance. 27, (2010), 30-46. 